trường hợp sử dụng vạt nhánh xuyên động mạch mu đốt bàn xuôi dòng và ngược dòng che phủ KHPM ngón tay khoảng cách nhận biết hai điểm phân biệt ở trạng thái tĩnh của vạt xuôi dòng là $8,3 \mathrm{~mm}$ vạt ngược dòng trung bình là $10,4 \mathrm{~mm}$.

Kết quả nghiên cứu của chúng tôi có sự tương đồng với kết quả nghiên cứu của các tác giả khác. Tất cả đều nhận thấy sự khác biệt về khả năng phục hồi cảm giác của các vạt dạng ngẫu nhiên sớm hơn và tốt hơn các vạt dạng trục mạch. Các vạt di chuyển xuôi dòng phục hồi cảm giác tốt hơn các vạt di chuyển ngược dòng.

\section{KẾT LUẬN}

Có nhiều yếu tố khác nhau ảnh hưởng đến kết quả tạo hình khuyết hổng phần mềm ngón tay bằng vạt cuống liền tại chỗ. Trong đó yếu tố nguồn cấp máu tại vạt và cách thức di chuyển của vạt dạng xuôi dòng hay ngược dòng có mối liên quan chặt chẽ đến mức độ sống và khả năng phục hồi cảm giác tại vạt. Vạt ngẫu nhiên di chuyển xuôi dòng có mức độ sống cao nhất và có khả năng phục hồi cảm giác sớm nhất và tốt nhất.

\section{TÀI LIÊU THAM KHẢO}

1. Beasley, R.W. (1983). Principles of soft tissue replacement for the hand. The Journal of Hand Surgery 8(5):781-784.

2. De, S.D. and M. Sandeep J. Sebastin (2020). Soft tissue coverage of the digits and hand. Hand Clin, 36(1):97-105.

3. Rehim, S.A. and K.C. Chung (2015). Local Flaps of The Hand. Hand Clin, 2014 May ; 30(2) 137-151.

4. Atasoy, E., et al. (1970). Reconstruction of the Amputated Finger Tip with a Triangular Volar Flap J Bone Joint Surg Am, 52(5), pp 921-926.

5. Aboulwafa, A. and S. Emara (2013). Versatility of Homodigital Islandized Lateral V-Y Flap for Reconstruction of Fingertips and Amputation Stumps. Egypt, J. Plast. Reconstr. Surg., Vol. 37, No. 1, January: 89-96, 2013.

6. Chen, $C_{\text {., }} \mathbf{W}$. Zhang, and P. Tang (2014). Direct and reversed dorsal digito-metacarpal flaps: A review of 24 cases. Care Injured, 45:805-812.

7. Sungur, N., et al. (2012). Bilateral V-Y rotation advancement flap for fingertip amputations. American Association for Hand Surgery 2012, 7:79-85.

8. Hastings, H. (1987). Dual innervated index to thumb cross finger or island flap reconstruction. Microsurgery, 8(3):168-172.

\title{
NGHIÊN CỨU CÁC YẾU TỐ NGUY CƠ LÀM TĂNG TỶ LÊ MẮC HUYẾT KHỐI TĨNH MẠCH SAU PHẪU THUẬT TIM NGỰC
}

\section{TÓM TẮT}

Nghiên cứu được thực hiện nhằm xác định tỷ lệ và các yếu tố nguy cớ huyểt khối tĩnh mạch ở người bệnh phẫu thuật tim ngực bằng việc áp dụng mô hình thang điểm nguy cơ Caprini hiệu chỉnh. Nghiên cứu sử dụng thiết kể mô tả cẵt ngang được tiến hành trên 35612 người bệnh phẫu thuật tim ngực từ $1 / 2017$ đến 12/2018. Tất cả người bệnh được đánh giá điểm nguy cơ trước phẫu thuât và được theo dõi trong vòng 30 ngà̃y sau phẫu thuật. Kết quả cho thấy tỷ lệ HKTM sau phẫu thuất tim ngức 30 ngày là $0,22 \%$ (78/35612). Nguy cơ mắc HKTM ở người có tổng điểm caprini 7-8 điểm cao gấp 7,13 lần so với người bệnh ở nhóm điểm Caprini 0-2. Các yễú tố nguy cơ làm tăng khả năng mắc HKTM sau phẫu thuật bao gồm: Tuổi, giới tính, suy tĩnh mạch ngoại vi ${ }_{L}$ tiểu đường và đặc biệt là tiên sử huyết khối trước phầu thuật.

Tư khóa: Huyết khối tĩnh mạch, phẫu thuật tim ngực, yếu tố nguy cơ, điểm Caprini

\footnotetext{
${ }^{1}$ Trường Đại học Y Hà Nội

²Bệnh viện Bạch Mai

Chịu trách nhiệm chính: Bùi Mỹ Hạnh

Email: buimyhanh@hmu.edu.vn

Ngày nhận bài: 10.5.2021

Ngày phản biện khoa học: 28.6.2021

Ngày duyệt bài: 9.7.2021
}

\section{Bùi Mỹ Hạnh ${ }^{1}$, Dương Đức Hùng ${ }^{2}$, Đoàn Quốc Hưng ${ }^{1}$}

\section{SUMMARY}

\section{RISK FACTORS OF VENOUS THROMBOEMBOLISM AFTER THORACIC SURGERY: A CASE-CONTROL STUDY FROM NATIONAL INSURANCE DATA}

Venous thromboembolism is an uncommon complication after thoracic surgery. However, it is a dangerous complication because it is often overlooked due to its infrequent and silent symptoms. The study is carried out to determine the rate and risk factors of venous thrombosis in patients who experienced thoracic surgery by applying adjusted Caprini risk assessement model. This study using descriptive cross section design was conducted on 35,612 patients undergoing thoracic surgery from $1 / 2017$ to $12 / 2018$. All patients were assessed for risk prior to surgery and supervised for 30 days postoperatively. The results showed that the rate of venous thromboembolism after 30-day thoracic surgery was calculated as $0.22 \%$ (78/35612). The risk of developing postoperative venous thromembolism in patients with a total caprini score of 7-8 points was estimated as 7.13 times which is higher than that of patients in the group with Caprini score 0-2. The risk factors increasing the likelihood of postoperative venous thromboembolism include: Age, sex, peripheral vascular disease, varicose cein, diabetes and especially history of thrombosis. 
Keywords: Venous thromboembolism, cardiothoracic surgery, risk factor, Caprini score

\section{I. ĐẶT VẤN ĐỀ}

Huyết khối tĩnh mạch không phải là biến chứng thường gặp sau phẫu thuật tim ngực. Tuy nhiên nó là biến chứng nguy hiểm vì hay bị bỏ sót do ít gặp và các triệu chứng thầm lặng [1]. Để xác định nguy cơ mẳc HKTM một cách chính xác cho người bệnh phẫu thuật, nhiều hệ thống thang điểm xếp hạng nguy cơ và phân loại người bệnh theo các nguy cơ đã được phát triển để phục vụ trong thực hành lâm sàng, nổi bât nhất của Caprini, Kucher, Cohen và hướng dẫn của NICE [2]. Thang điểm Caprini đã được phát triển từ hơn hai thập kỷ trước, dựa trên sự kết hợp giữa kinh nghiệm lân sàng và các dữ liệu được công bố, và đã được các nhà nghiên cứu chứng minh là có độ nhạy và độ đặc hiệu cao. Ngoài việc đánh giá và phân tầng nguy cớ, mô hình cũng đưa ra các khuyến cáo phù hợp để điều trị dự phòng HKTM theo điểm số và mức độ nguy cớ. Một vài phiên bản hiệu chỉnh của mô hình Caprini trên người bệnh đã̉ được công bố bởi các nghiên cứu khác nhau [3-5]. Tại Việt Nam, các nghiên cứu về đánh giá nguy cơ mắc HKTM theo thang điểm Caprini sau phẫu thuật tim ngực vẫn còn hạn chế. Vì vậy, chúng tôi thực hiện nghiên cứu với mục tiêu là

1. Xác định tỷ lệ huyết khối tĩnh mạch ở người bệnh phẫu thuật tim ngực

2. Đánh giá các yếu tố nguy cơ mắc HKTM sau phẫu thuật tim ngực theo mô hinh Caprini hiẹu chinh.

\section{II. ĐỐl TƯƠNGG VÀ PHƯƠNG PHÁP NGHIÊN CỨU}

1. Thời gian và địa điểm nghiên cứu. Nghiên cứu được thực hiện trong khoảng thời gian từ $1 / 2017$ đến 12/2018 từ dữ liệu chuyển lên hệ thống dữ liệu bảo hiểm quốc gia của tất cả các bênh viên trên cả nước.

\section{2. Đối tượng nghiên cứu}

Tiêu chuẩn lựa chôn: Người bệnh >18 tuổi được thực hiện các phẫu thuật tim ngực.

Tiêu chuẩn loại trừ: Người bênh được chẩn đoán xác định mắc HKTM tại thời điểm tham gia nghiên cứu, hoặc đang trong giai đoạn điều trị huyết khối, hoặc chống chỉ định sử dụng thuốc chống đông, hoặc đang sử dụng thuốc kháng tiểu cầu.

Cỡ mẫu thu được $n=35.612$

\section{Phương Pháp}

Thiết kế nghiên cứu: Mô tả cắt ngang

Mô hình đánh giá nguy cơ theo Caprini được áp dụng và sử dụng hệ thống chấm điểm cho từng yếu tố nguy cơ được cộng lại để tạo thành điểm số nguy cơ tích lũ̃y để xác định mức độ nguy cơ HKTM của người bệnh thấp, vừa, cao và cao nhất. Mô hình đánh giá nguy cơ đã được hiệu chỉnh chỉ bao gồm các tiêu chí quan sát được trong báo cáo dữ liệu của bệnh viện. Các thông số xét nghiệm như yếu tố Leiden $V$, homocysteine huyết thanh, kháng thể kháng cardiolipin, prothrombin 20210A, chất chống đông lupus được loại khỏi mô hình vì hầu hết không có chỉ định tiển hành. Tính hợp lệ và hiệu quả của mô hình Caprini hiệu chỉnh đã được chứng minh trong các nghiên cứu trước đây của chúng tôi [6].

Quy trình nghiên cứu. Dữ liệu lâm sàng người bệnh phẫu thuật được thu thập tại các bệnh viện và được chuyển lên hệ thống dữ liệu bảo hiểm quốc gia. Các yếu tố nguy cơ ở người bệnh được đánh giá và tổng hợp để xác định điểm số nguy cơ tích loại và xêp hạng mức độ nguy cơ HKTM.

Chẩn đoán HKTM ở người bệnh phẫu thuật được được tiến hành dựa theo Khuyến cáo về chẩn đoán, điều trị và dự phòng thuyên tắc huyết khối tĩnh mạch của Hội tim mạch quốc gia Việt Nam năm 2016. Người bệnh có triệu chứng nghi ngờ mắc HKTM sẽ được tiến hành chẩn đoán xác định bằng siêu âm Dupplex, chụp cộng hưởng từ (MRI) tĩnh mạch hoăc siêu âm Doppler; Các trường hợp nghi mắc thuyên tắc phổi sẽ được chẩn đoán qua chụp căt lớp vi tính (CT), hoặc chụp động mạch phổi. Các dấu hiệu và triệu chứng lâm sàng của HKTM được đánh giá cứ sau $3-5$ ngày trong thời gian 30 ngày sau phẫu thuật ở người bệnh điều trị nội trú. Người bệnh bị nghi ngờ mắc HKTM sâu khi nhận thấy các triêu chứng sưng và đau ở một hoặc hai bên chân (thường ở vị trí bắp chân), cảm giác đau nhức khi đi bộ, đứng hoặc co gập chân, sờ thây ấm ở vị trí bị sưng, và ban đỏ ở chân được phát hiện. Đối với thuyên tắc phổi, các trường hợp bị nghi mắc bao gồm khó thở không rõ nguyên nhân, đau ngực khi hít vào, ho ra máu, thở gấp và nhịp tim nhanh. Đối với người bệnh ra viện trước 30 ngày, các triệu chứng của HKTM được theo dõi đánh giá qua hệ thống liên lạc thông thường của bệnh viện. Trong thời gian điều trị và sinh hoạt tại nhà, người bệnh được hướng dẫn báo cáo cho bộ phận ngoại trú hoặc đến cơ sở điều trị nếu phát sinh bất kỳ triệu chứng nghi ngờ HKTM.

4. Phân tích thống kê. Dữ liệu được phân tích bằng phần mềm hể thống STATA 20.0. Các biến liên tục được mô tả dưới dạng trung bình 
hoặc trung vị, các biến phân loại được biểu thị dưới dạng tần số tỷ lệ (\%).

Kiểm định Chi-square và Fisher test được sử dụng để đánh giá sự khác biệt về nguy cơ mắc HKTM giữa các nhóm điểm Caprini. Mô hình phân tích đa biến hồi quy logictic để đánh giá ảnh hưởng của các thành tố của thang điểm như tuổi, giới tính, ung thư, sự xuất hiện của bệnh kèm theo và tiền sử mắc thuyên tắc huyết khối tĩnh mạch... Kết quả có ý nghĩa thống kê với giá trị $p<0,05$.

5. Đạo đức nghiên cứu. Nghiên cứu đã được sự chấp thuận của Hội đồng Đạo đức của Trường Đại học Y Hà Nội số 67/HĐĐĐĐHYHN ngày $24 / 3 / 2017$.

\section{KẾT QUẢ NGHIÊN CỨU}

3.1. Tỷ lệ mắc HKTM ở người bệnh sau phấu thuật tim ngực

Bảng 1. Đặc điểm của người bệnh $(n=35.612)$

\begin{tabular}{|c|c|c|c|}
\hline \multicolumn{2}{|c|}{ Đặc điếm } & $\mathbf{n}$ & $\mathbf{\%}$ \\
\hline \multirow{3}{*}{ Giới } & Nam & 23253 & 65,3 \\
\cline { 2 - 4 } tính & Nữ & 12359 & 34,7 \\
\cline { 2 - 4 } & Tống & 35612 & 100,0 \\
\hline \multirow{4}{*}{ Tuổi } & $18-40$ & 11377 & 31,9 \\
\cline { 2 - 4 } & $41-60$ & 14868 & 41,8 \\
\cline { 2 - 4 } & $61-74$ & 7472 & 20,9 \\
\cline { 2 - 4 } & $>74$ & 1895 & 5,3 \\
\cline { 2 - 4 } & Tống & $\mathbf{3 5 6 1 2}$ & $\mathbf{1 0 0}$ \\
\hline
\end{tabular}

Nhận xét: Nam giới (65,3\%) chiếm tỷ lệ cao hơn so với nữ giới $(34,7)$. Nhóm tuổi $41-60$ là nhóm tuổi có số người bệnh trải qua phẫu thuật tim ngực cao nhất chiếm 41,8\%.

Bảng 2. Tỷ lệ mắc HKTM phân loại theo nhóm điểm Caprini hiệu chỉnh (n=35.612)

\begin{tabular}{|c|c|c|c|c|c|c|}
\hline $\begin{array}{c}\text { Điểm } \\
\text { Caprini }\end{array}$ & $\begin{array}{c}\text { Số NB phấu } \\
\text { thuật }\end{array}$ & $\begin{array}{c}\text { Số NB mắc } \\
\text { HKTM }\end{array}$ & $\begin{array}{c}\text { Tỷ lệ mắc HKTM theo } \\
\text { tứng nhóm (\%) }\end{array}$ & RR & $\mathbf{9 5 \%} \mathbf{0 I}$ & $\mathbf{p}$ \\
\hline 0-2 điếm & 10716 & 13 & 0,12 & & & \\
\hline 3-4 điếm & 15092 & 31 & 0,21 & 1,69 & $0,89-3,23$ & 0,11 \\
\hline 5-6 điểm & 7130 & 17 & 0,24 & 1,96 & $0,95-4,04$ & 0,06 \\
\hline 7-8 điểm & 1618 & 14 & 0,87 & 7,13 & $3,36-15,15$ & $<0,01$ \\
\hline$>8$ điếm & 1056 & 3 & 0,28 & 2,34 & $0,67-8,2$ & 0,19 \\
\hline Tống & $\mathbf{3 5 6 1 2}$ & $\mathbf{7 8}$ & $\mathbf{0 , 2 2}$ & & & \\
\hline
\end{tabular}

Nhận xét: Tỷ lệ mắc HKTM là 0,22\% (78/35612). Người bệnh có tổng điểm Caprini 7-8 điểm có nguy cớ mắc HKTM sau phẫu thuật cao nhất gấp 7,13 lần so với người bệnh ở nhóm điểm Caprini 02. Sự khác biệt có ý nghĩa thống kê với $p<0.001$.

3.2. Độ tin cậy của hệ thống thang điểm Caprini hiệu chỉnh trong phân tích nguy cơ HKTM Bảng 3. Tỷ suất OR mắc HKTM ở người bệnh phầu thuật tìm ngực giữa các nhóm điểm Caprini hiệu chinh

\begin{tabular}{|c|c|c|c|}
\hline Diểm Caprini & $\mathbf{5 - 6}$ điểm & $\mathbf{7 - 8}$ điểm & $\mathbf{8}$ điểm \\
\hline $3-4$ điểm & $\begin{array}{c}1,16(0,64-2,1) \\
\mathrm{p}<0,621\end{array}$ & $\begin{array}{c}4,24(2,25-7,99) \\
\mathrm{p}<0,001\end{array}$ & $\begin{array}{c}0,97(0,3-3,18) \\
\mathrm{p}=0,96\end{array}$ \\
\hline 5-6 điểm & & $3,65(1,8-7,42) ; \mathrm{p}<0,001$ & $1,19(0,35-4,07) ; \mathrm{p}=0,779$ \\
\hline $7-8$ điếm & & & $0,33(0,09-1,14) ; \mathrm{p}=0,079$ \\
\hline
\end{tabular}

Nhận xét: Bảng 3 cho thấy, nhóm người bệnh có tổng điểm Caprini hiệu chỉnh 7-8 điểm có nguy cơ mắc HKTM sau phẫu thuật tim ngực cao hơn so với các nhóm NB có tổng điểm Caprini hiệu chỉnh $3-4,5-6,>8$ với OR lần lượt là 4,24, 3,65.

3.3. Xác định yếu tố nguy cơ HKTM sau phẫu thuật tim ngực

Bảng 4. Yếu tố nguy cơ HKTM theo mô hình đánh giá ngưy cơ theo thang điểm Caprini hiệu chinh

\begin{tabular}{|c|c|c|c|c|c|c|}
\hline \multicolumn{2}{|c|}{ Đăc điếm } & Tống số & Có HKTM & $\mathbf{R R}$ & 95\% CI & $\mathbf{p}$ \\
\hline \multirow{2}{*}{$\begin{array}{l}\text { Giới } \\
\text { tính }\end{array}$} & Nam & 23253 & 43 & 1 & & \\
\hline & Nữ & 12359 & 35 & 1,53 & $0,98-2,39$ & 0,06 \\
\hline \multirow{4}{*}{$\begin{array}{l}\text { Nhóm } \\
\text { tuổi }\end{array}$} & $18-40$ & 11377 & 15 & 1 & & \\
\hline & $41-60$ & 14868 & 39 & 1,99 & $1,1-3,61$ & 0,02 \\
\hline & $61-74$ & 7472 & 21 & 2,13 & $1,1-4,13$ & 0,03 \\
\hline & $>74$ & 1895 & 3 & 1,2 & $0,35-4,14$ & 0,77 \\
\hline \multirow{4}{*}{$\begin{array}{c}\text { Bệnh } \\
\text { trước } \\
\text { PT }\end{array}$} & Nhồi máu cơ tim & 405 & 2 & 2,29 & $0,56-9,28$ & 0,24 \\
\hline & Xơ vữa động mạch & 41 & 0 & 5,39 & $0,34-85,59$ & 0,23 \\
\hline & Mạch máu não & 1733 & 5 & 1,34 & $0,54-3,31$ & 0,52 \\
\hline & Bất động >72 giờ & 142 & 0 & 1,58 & $0,09-25,36$ & 0,74 \\
\hline
\end{tabular}


VIETNAM MEDICAL JOURNAL N² - JULY - 2021

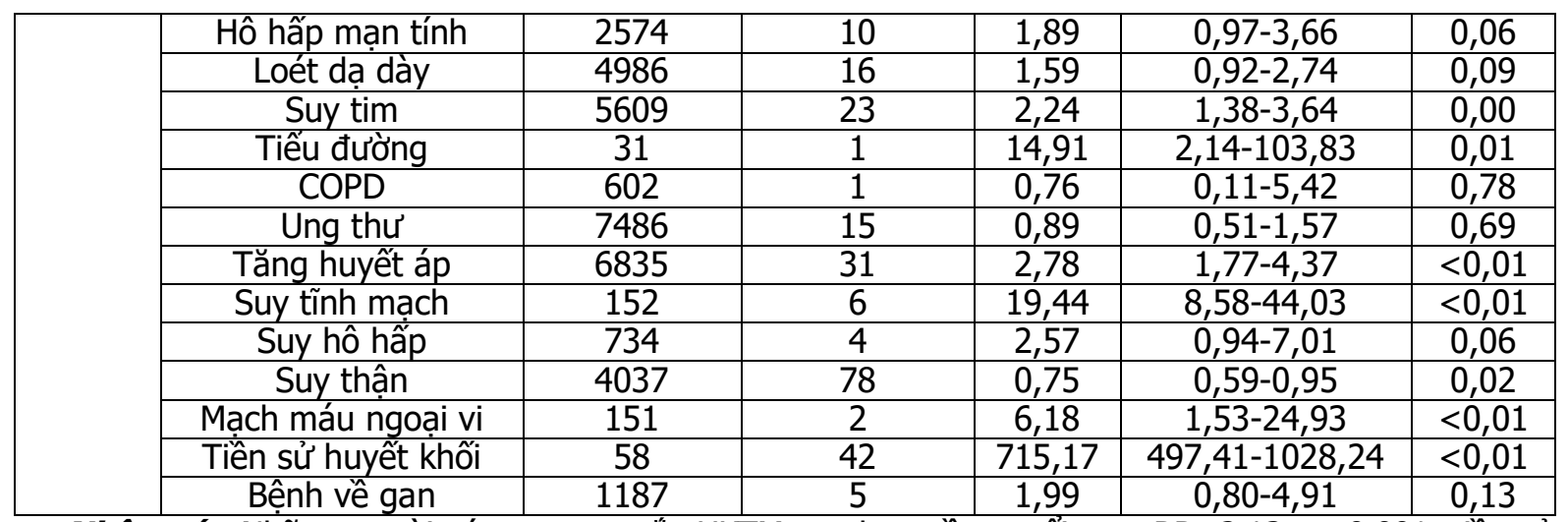

Nhân xét: Những người có nguy cơ mắc HKTM cao bao gồm: tuối cao, $R R=2,13, p<0,001$; tiền sứ mắc HKTM, $R R=715,17, p<0,001$; suy tĩnh mạch, $R R=19,44, p<0,001$; tiểu đường, $R R=14,91, p<0,05$.

\section{BÀN LUÂN}

4.1. Tỷ lệ huyết khối tĩnh mạch. Tỷ lệ mắc huyết khối tĩnh mạch sau phẫu thuật tim ngực là 0,22\% (78/35612 người). Các số liệu mô tả cắt ngang cho thây số nam giới thực hiện phẫu thuật tim ngực cao hơn so với nữ, nhóm tuổi 1840 và 41-60 là hai nhóm chiếm tỷ lệ cao nhất. So với các nghiên cứu yếu tố nguy cớ HKTM được chúng tôi thực hiện trên nhóm phẫu thuật khác, tỷ lệ mắc HKTM ở người bệnh phẫu thuật tim ngực trong nghiên cứu của chúng tôi có kểt quả thấp hơn có thể do các yếu tố nguy cơ HKTM ở loại phẫu thuật này thấp hơn hoặc đã được kiểm soát tốt hơn từ trước - trong cũng như sau phẫu thuật. Nghiên cứu ứng dụng thang điểm Caprini ở người bênh phẫu thuật chấn thương chỉnh hình và phẫu thuật thần kinh cho tỷ lệ mắc HKTM sau phâuu thuật lần lượt là $0,14 \%$ và $0,46 \%[6],[4]$. Trong khi đó ở người bệnh phẫu thuật nói chung cho kết quả gần tương đương $0,11 \%[3]$. Bên cạnh đó, kết quả nghiên cứu cũng thấp hơn với nghiên cứu trên cùng loại phẫu thuật của tác giả Balachandran với tỷ lệ mới mắc là $1,1 \%[1]$. Sự khác biệt về kết quả này có thể bắt nguồn sự khác nhau trong quần thể nghiên cứu, tỷ lệ người bệnh được dự phòng chống đông, thời gian và loại hình điêu trí.

4.2. Đánh giá yếu tố nguy cơ. Tương tự như các nghiên cứu trước của nhóm nghiên cứu tại Việt Nam, ứng dụng mô hình Caprini hiệu chỉnh cho thấy tỷ lệ mắc HKTM sau phẫu thuật tim ngực tăng tỷ lệ thuận theo nhóm điểm Caprini hiệu chỉnh lần lượt là $0,12 \%$ (0-2 điểm), 0,21\% (3-4 điểm), 0,24\% (5-6 điểm), 0,87\% (78 điểm), $0,28 \%$ ( $>8$ điểm). Nghiên cứu chúng tôi chỉ ra điểm số nguy cơ hiệu chỉnh càng cao thì nguy cơ HKTM càng tăng, trong đó người bệnh có tổng điểm Caprini 7-8 có nguy cơ mắc HKTM sau phẫu thuật cao nhất với nguy cơ tương đối
(RR) là 7,13 . Tương tự, nguy cơ HKTM tăng dần theo số điểm Caprini đã được chứng minh trong nghiên cứu quốc tế của chúng tôi ở người bệnh phẫu thuật nói chung với tỷ lệ mới tăng từ $0,04 \%$ tới $0,45 \%[3]$. Bên cạnh đó, tác giả Bahl và cộng sự cũng cho thấy tỷ lệ HKTM tăng rõ rệt ở nhóm người bệnh nguy cớ cao nhất (điểm Caprini $\geq 5$ ), với tỷ lệ HKTM lên tới $2,58 \%$ và $6,51 \%$ lần lượt ở hai nhóm người bệnh có điểm nguy cơ tích lũy $7-8$ và $>8$. Việc sử dụng thang điểm hiệu chỉnh để phân loại người bệnh có nguy cơ cao nhất tạo điều kiện thuận lợi để phát hiện người bệnh nguy cơ cao một cách kịp thời để đưa ra các can thiêp dự phò̀ng huyểt khối một cách phù hợp và hiệu quả, do đó giảm thiểu các biến chứng có thể gây ra bởi liệu pháp dự phòng huyết khối.

Nghiên cứu chúng tôi đã chỉ ra sự khác biệt nguy cơ mắc HKTM sau phẫu thuật tim ngực giữa các nhóm người bệnh có nguy cơ cao. So với nhóm người bệnh có điểm số nguy cơ tích lũy Caprini 3-4, nhóm 7-8 điểm có nguy cơ mắc HKTM gấp 4,24 lần. Nghiên cứu của tác giả Pannuci về phương pháp chấm điểm nguy cơ dựa trên mô hình Caprini, đã chỉ ra nguy cơ tăng rõ rệt ở nhóm người bệnh có điểm số nguy cơ tích lũy $\geq 5[2]$. Bên cạnh đó, tác giả Kanchan và cộng sự đã chỉ ra nguy cơ HKTM sau phẫu thuật tắng 67,5 lần ở nhóm người bệnh có điểm 7-8 và tăng 153,5 lần ở nhóm người bệnh có điểm Caprini $>8$ khi so sánh với nhóm có điểm Caprini 3-4[7]. Như vậy, việc phân loại theo 4 mức nguy cơ, đặc biệt ở nhóm người bềnh nguy cơ cao là rất hữu ích trong xác định chính xác mức độ nguy cơ ở từng đối tượng cụ thể.

Người bệnh phẫu thuât tim ngực có các yếu tố như tình trạng cao tuổi, giới tính nữ, suy tĩnh mạch, người bệnh có tiền sử mắc huyết khối tĩnh mạch sâu, tiểu đường có nguy cơ cao mắc HKTM 
sau phẫu thuật. Kết quả nghiên cứu của chúng tôi phù hợp với các nghiên cứu y khoa trước đây. So với các nghiên cứu áp dụng thang điểm Caprini hiệu chỉnh được tiến hành trước đây của chúng tôi[6],[5],[4] nghiên cứu này cho thấy sự tương đồng về các yếu tố nguy cơ mắc HKTM sau phẫu thuật. Việc đánh giá đúng các yếu tố nguy cơ HKTM trưởc phẫu thuâtt sẽ giúp bác sĩ đưa ra liệu pháp dự phòng để giảm thiểu các gánh nặng về biến chứng cũng như chi phí cho người bệnh.

\section{KẾT LUÂNN}

Tỷ lệ mắc của HKTM ở người bệnh sau phẫu thuật tim ngực là $0,22 \%$ và tăng dần theo từng nhóm điểm Caprini hiêuu chỉnh là $0,12 \%(0-2$ điểm), 0,21\% (3-4 điểm), 0,24\% (5-6 điểm), $0,87 \%$ ( $7-8$ điểm) và $0,28 \%$ (>8 điểm). Nguy cơ mắc huyết khối tînh mạch tăng tỷ lệ thuận theo điểm số nguy cơ tích lũ̃y với tỷ suất chênh (OR) cao nhất ở nhóm Caprini $\geq 5$ điểm lần lượt là $1,16,4,24$ ở các nhóm điểm Caprini 5-6 điểm, và 7-8 điểm so với nhóm có tổng điểm Caprini hiệu chỉnh 3-4 điểm. Các yếu tố nguy cơ ở người bênh phẫu thuật tim ngực được ghi nhận là giới tính nữ, tuổi già, tiền sử mắc huyết khối tĩnh mạch, các bệnh suy tĩnh mạch, tiểu đường.

\section{TÀI LIỆ THAM KHẢO}

1. Balachandran $R$, Jensen $K K$, Burcharth J et al. (2020), "Incidence of Venous Thromboembolism Following Major Emergency Abdominal Surgery", World J Surg, 44(3), 704-710.

2. Fleming KI and Pannucci CP' (2018), "Comparison of face-to-face interaction and the electronic medical record for venous thromboembolism risk stratification using the 2005 Caprini score", J Vasc Surg Venous Lymphat Disord, 6(3), 304-311.

3. Bui My Hanh, Le Quang Cuong và Nguyen Truong Son et al (2019), "Determination of risk factors for venous thromboembolism by Adapted Caprini scoring system in surgical patients", Journal of Personalized Medicine, 9(3), 36.

4. Bùi Mỹ Hạnh, Đoàn Quốc Hưng và Hoàng Thị Hồng Xuyến (2019), "Ứng dung thang điểm Caprini hiệu chỉnh trong đánh giá ñguy cơ huyết khối tĩnh mạch trên người bệnh phẫu thuật mạch máu", Tap chí nghiên cứu y hoc, 122(6), 344-350.

5. Bùi Mỹ Hanh, Đào Xuân Thành và Đoàn Việt Quân (2019), "Khảo sát một số yếu tố nguy cớ của Huyết khối tĩnh mach ở bệnh nhân sau phẫu thuật chấn thương chỉnh hình", Tạp chí nghiên cứu y hoc, 121(5), 81-88.

6. Lê Tuấn Linh Bùi Mỹ Hạnh, Nguyễn Thế Hào và cộng sứ (2019), "Áṕ dụng hế thống thang điểm Caprini hiệu chính trong đán giá mức độ và nhận biết yếu tố nguy cơ huyết khối tĩnh mach trên người bệnh phâuu thuật thân kinh", Tạp chí Y học thực hành, 11(1118), 78-81.

7. Kanchan B, Anitha M Mohsina S et al (2016), "Assessing the risk for development of Venous Thromboembolism (VTE) in surgical patients using Adapted Caprini scoring system", Int J Surg, 30, 68-73.

\section{ĐĂC ĐIỂM BỂNH VÕNG MAC ĐÁI THÁO ĐƯỜNG TRÊN BÊNHH NHÂN ĐÁI THÁO ĐƯỜ'NG TÝP 2 TẠII BÊ̂NH VIỆN TRUNG ƯƠNG THÁI NGUYÊN}

\section{TÓM TẮT}

Muc tiêu: Mô tả đăc điểm bênh võng mạc đái tháo đường trên bênh nhân đái tháo đường týp 2 tai BV Trung Ương Thái Nguyên. Đối tượng và phương pháp: Nghiên cứu được tiến hành trên 395 bênh nhân đái tháo đường týp 2 được điều trị ngoại trú tại BV Trung Ương Thái Nguyên. Nghiên cứu mô tả cắt ngang. Kết quả: Thời gian mắc bệnh của bệnh nhân trong nghiên cứu chủ yếu là từ 10-20 năm (chiếm $58,5 \%)$, thị lực sau chỉnh kính đạt mức tốt chiếm $61,5 \%$, mức giảm đạt $15,4 \%$, và có $4,4 \%$ thị lực ở

*Trường Đại học Y Dược Thái Nguyên

**Trướng Đai hoc Y Hà Nối

Chịu trách nhiệm chính: Lương Thị Hải Hà

Email: haihamat@gmail.com

Ngày nhận bài: 11.5.2021

Ngày phản biên khoa họ: 28.6.2021

Ngày duyệt bài: 12.7.2021
Lương Thị Hải Hà*, Đặng Đức Minh*, Hoàng Thị Phúc**, Mai Quốc Tùng**.

mức mù, có 73/395 trường hợp có tổn thương VM do đái tháo đường (chiếm 18,5\%) trong đó các hình thái tổn thương hay gặp nhất là vi phình mạch, xuất tiết võng mac và xuất huyết võng mac, $63 \%$ trường hợp có tổn thương võng mạc ở giai đoạn chưa tăng sinh và $37 \%$ tổn thương võng mạc tăng sinh. Kết luận: Có 18,5\% bệnh nhân có bệnh võng mạc đái tháo đường trong đó có $63 \%$ tổn thương võng mạc chưa tăng sinh và $37 \%$ tổn thương võng mạc tăng sinh.

Tư khóa: Thị lực, bệnh võng mạc đái tháo đường, đái tháo đường,...

Chữ viết tắt: Võng mạc (VM), võng mạc đái tháo đường (VMĐTĐ), đếm ngón tay (ĐNT), hoàng điểm (HĐ), đái tháo đường (ĐTĐ).

\section{SUMMARY \\ CHARACTERISTICS OF DIABETIC \\ RETINOPATHY IN THE PATIENTS WITH \\ DIABETES TYPE 2 IN THAI NGUYEN NATIONAL HOSPITAL}

